Supporting information

for

\title{
In-situ growth of cationic covalent organic frameworks (COFs) for mixed matrix membranes with enhanced performances
}

\author{
Xingyuan Wang, Xiansong Shi, and Yong Wang* \\ State Key Laboratory of Materials-Oriented Chemical Engineering and College of \\ Chemical Engineering, Nanjing Tech University, Nanjing 211816, P. R. China \\ E-mail: yongwang@njtech.edu.cn
}

Number of pages: 5

Number of figures: 7

Number of schemes: 0

Number of tables: 0

\section{Contents}

1. The formation of TpEB. (Figure S1-S3)

2. Characterizations of the membranes. (Figure S4-S6)

3. Long-term performance. (Figure S7) 

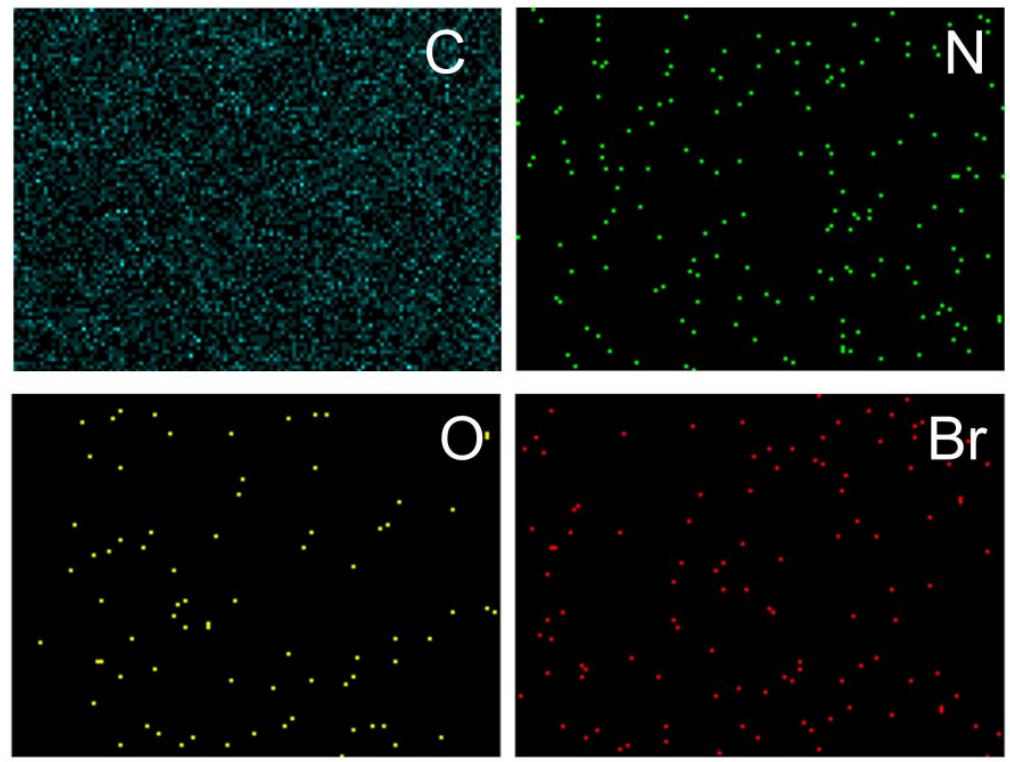

Figure S1. EDS mapping of the TpEB-PAN membrane with $1 \mathrm{wt} \%$ monomer pairs in the casting solution.

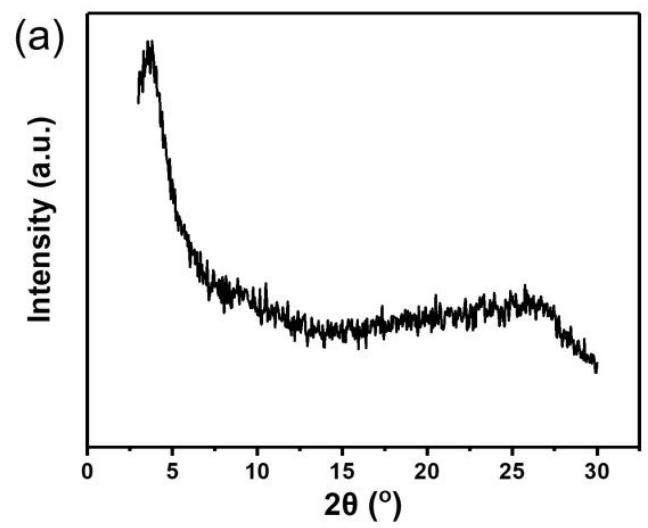

(b)

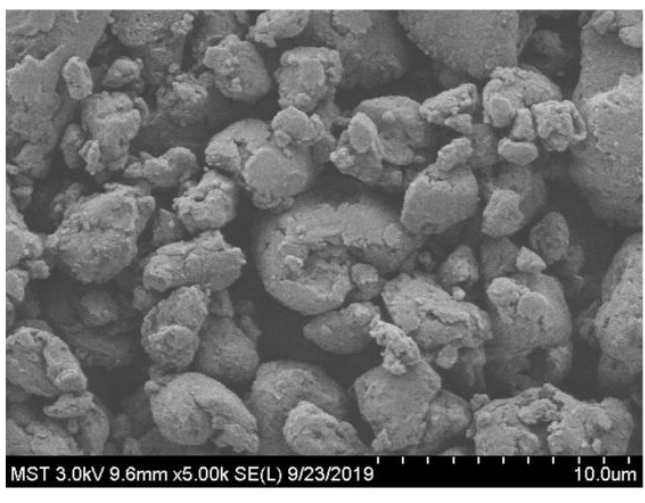

Figure S2. Characterizations of the TpEB particulates synthesized by thermal-solvent method. (a) XRD pattern; (b) SEM image. 


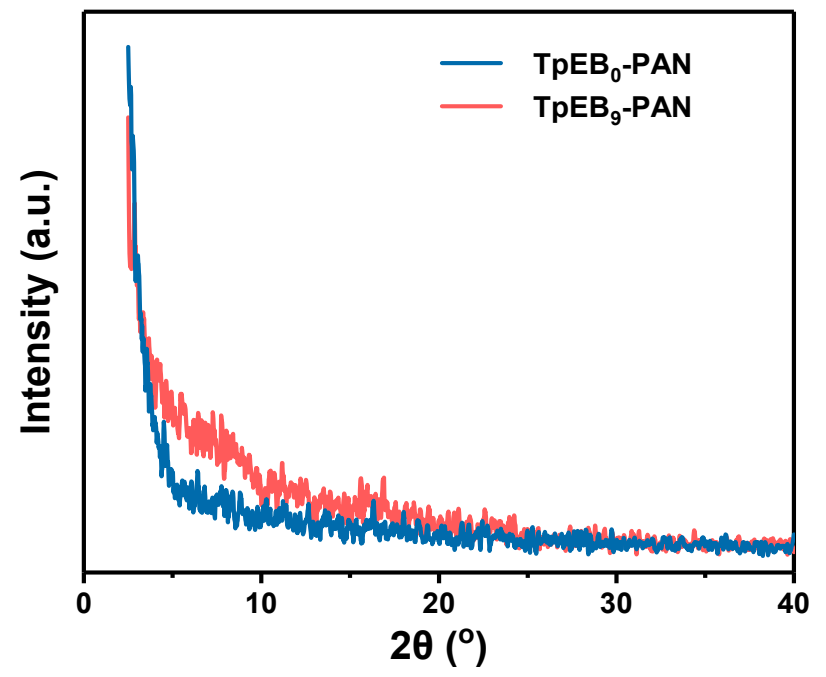

Figure S3. XRD patterns of $\mathrm{TpEB}_{9}-\mathrm{PAN}$ membrane and PAN membrane.

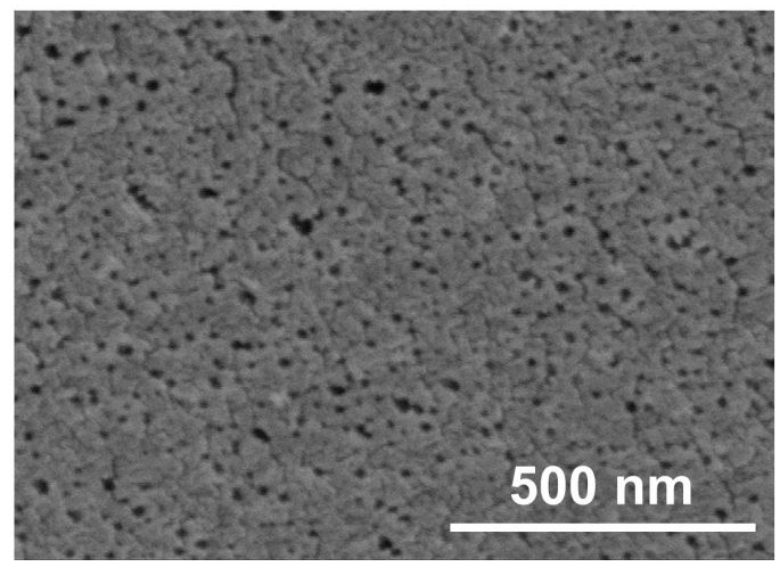

Figure S4. Surface morphology of the $\mathrm{TpEB}_{9}-\mathrm{PAN}$ membrane. 

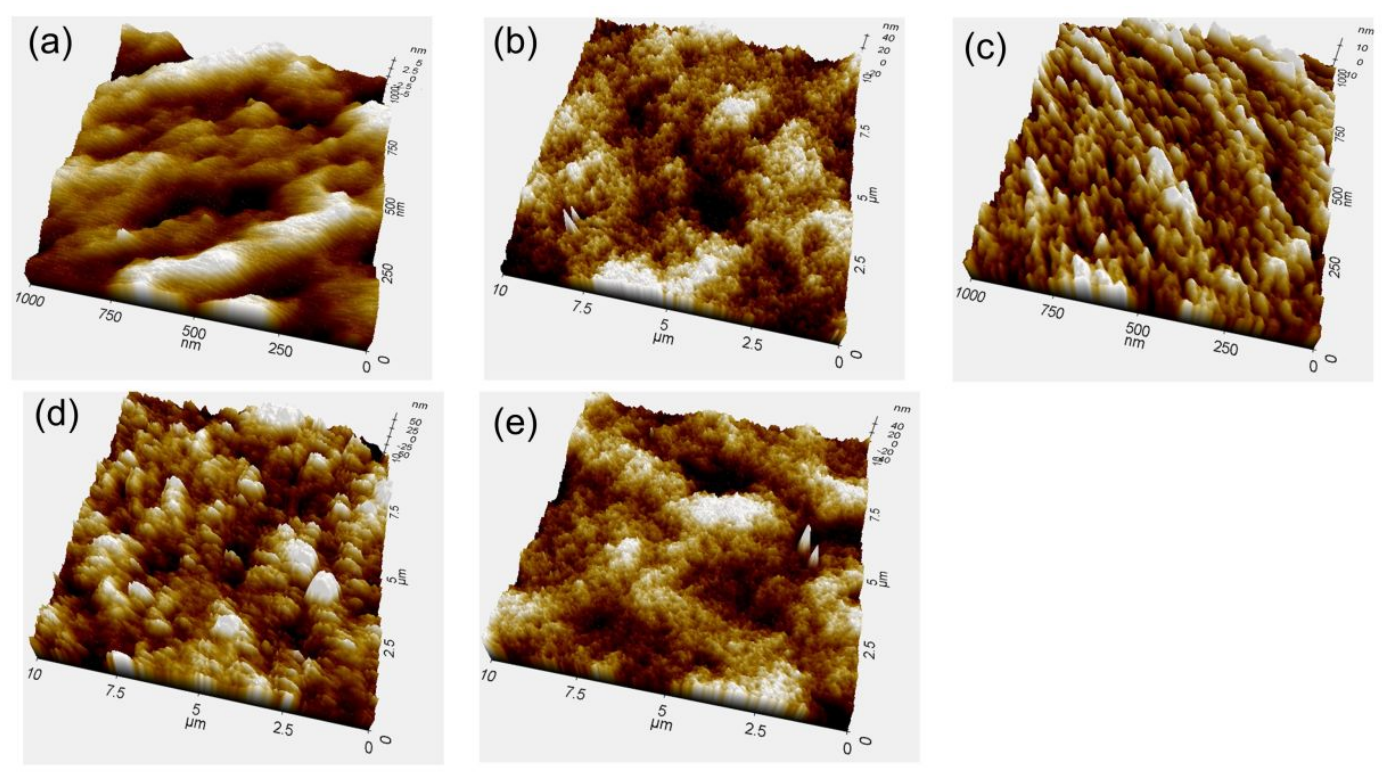

Figure S5. AFM topologies of the TpEB-PAN membranes with various monomer concentrations. (a) $0 \mathrm{wt} \%$; (b) $0.03 \mathrm{wt} \%$; (c) $0.05 \mathrm{wt} \%$; (d) $0.07 \mathrm{wt} \%$; (e) $0.09 \mathrm{wt} \%$.
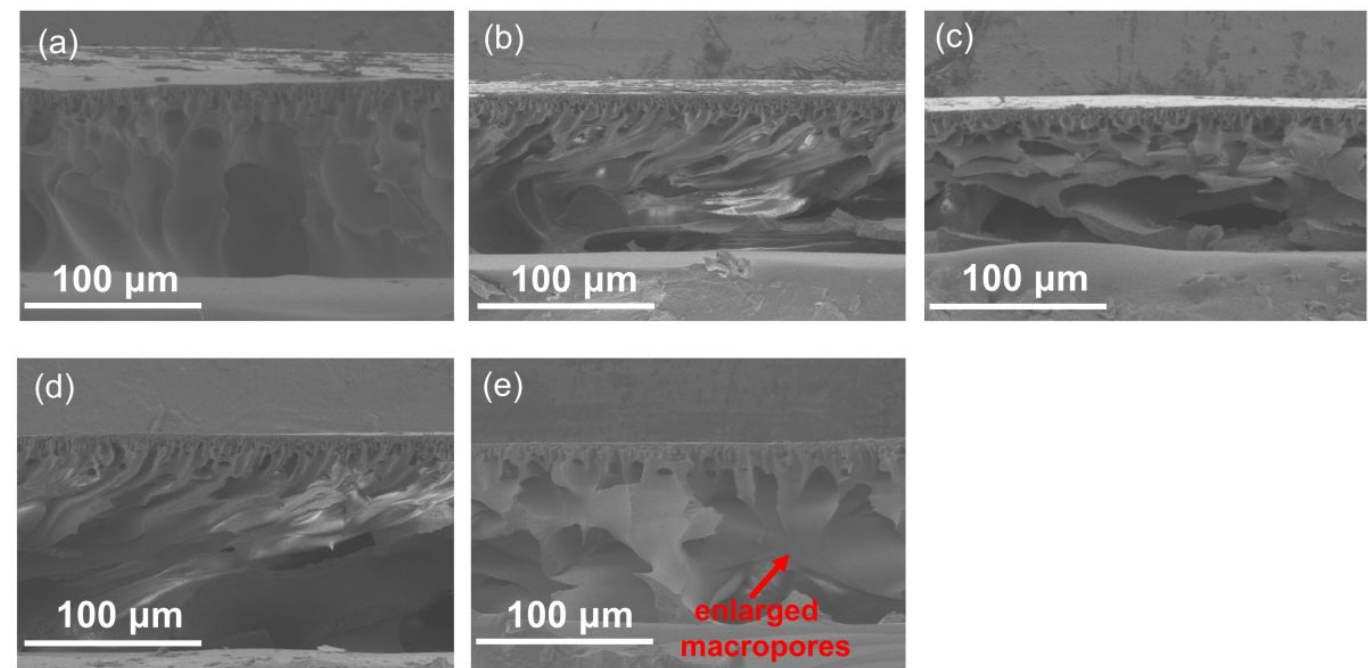

Figure S6. Cross-sectional morphologies of the self-standing TpEB-PAN membranes with various monomer concentrations. (a) $0 \mathrm{wt} \%$; (b) $0.03 \mathrm{wt} \%$; (c) $0.05 \mathrm{wt} \%$; (d) 0.07 $w t \%$; (e) $0.09 w t \%$. 


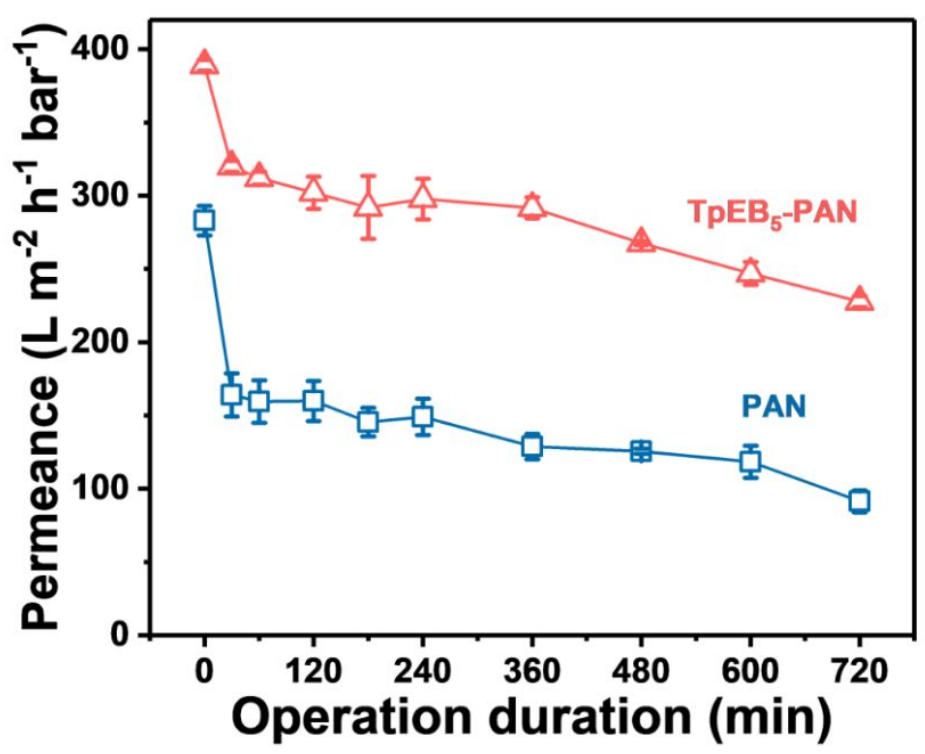

Figure S7. Long-term stability of the TpEB ${ }_{5}-\mathrm{PAN}$ and PAN membrane. 